\title{
Hsa-miR-875-5p exerts tumor suppressor function through down-regulation of EGFR in colorectal carcinoma (CRC)
}

\author{
Tiening Zhang ${ }^{1, *}$, Xun Cai ${ }^{1, *}$, Qi Li ${ }^{1}$, Peng Xue ${ }^{1}$, Zhixiao Chen ${ }^{1}$, Xiao Dong ${ }^{1}$, Ying Xue ${ }^{1}$ \\ 1Oncology Center, Shanghai General Hospital, Shanghai Jiaotong University, School of Medicine, Shanghai 200080, \\ P. R. China \\ *These authors contributed equally to this work
}

Correspondence to: Xun Cai, email: xuncaisjtu@sina.com

Keywords: hsa-miRNA-875-5p (miR-875-5p), EGFR, colorectal carcinoma (CRC), proliferation, apoptosis

Received: March 21, 2016

Accepted: April 09, 2016

Published: June 10, 2016

\section{ABSTRACT}

Hsa-miRNA-875-5p (miR-875-5p) has recently been discovered to have anticancer efficacy in different organs. However, the role of miR-875-5p on colorectal carcinoma (CRC) is still ambiguous. In this study, we investigated the role of miR875-5p on the development of CRC. The results indicated that miR-875-5p was significantly down-regulated in primary tumor tissues and very low levels were found in CRC cell lines. Ectopic expression of miR-875-5p in CRC cell lines significantly suppressed cell growth as evidenced by cell viability assay, colony formation assay and BrdU staining, through inhibition of cyclin D1, cyclin D2, CDK4 and up-regulation of p57(Kip2) and p21(Waf1/Cip1). In addition, miR-875-5p induced apoptosis, as indicated by concomitantly with up-regulation of key apoptosis protein cleaved caspase-3, and down-regulation of anti-apoptosis protein Bcl2. Moreover, miR875-5p inhibited cellular migration and invasiveness through inhibition of matrix metalloproteinases (MMP)-7 and MMP-9. Further, oncogene EGFR was revealed to be a putative target of miR-875-5p, which was inversely correlated with miR-875-5p expression in CRC. Taken together, our results demonstrated that miR-875-5p played a pivotal role on CRC through inhibiting cell proliferation, migration, invasion, and promoting apoptosis by targeting oncogenic EGFR.

\section{INTRODUCTION}

Colorectal carcinoma (CRC) is one of the leading causes of cancer mortality around the world, particularly in developed countries. If a patient is diagnosed at an advanced stage of CRC, his 5-year survival rate is only up to $10 \%[1,2]$. Clarification of the mechanisms that underlie $\mathrm{CRC}$ tumorigenesis and progression therefore is needed urgently $[4,5]$. Though alterations in oncogenes and tumour suppressor genes have been reported in CRC [6-8], the precise molecular mechanisms underlying CRC pathogenesis remain to be fully elucidated. MicroRNAs (miRNAs) are a class of small, highly conserved, and noncoding RNAs that directly target genes' 3'-untranslated regions (3'-UTRs) by binding to some sequence-specific sites, resulting in deceased expression of these genes [9-12]. Numerous of publications have confirmed that dysregulation of miRNAs play an important role in various types of cancers [9-16]. Selective miRNA expression contributes to tumor proliferation, apoptosis, senescence, cell identity, stem cell maintenance and metastasis [9-21]. While there are still numerous of unknown details about the role of miRNAs on human cancers that still need to be investigated [22].

MiR-875-5p (MIMAT0004922), is down-regulated in numerous of diseases, including neurodegenerative diseases [22], and cervical cancer cells [23]. It is also reported that miR-875-5p targets the HPV genomic sites, and negatively influences exogenous and endogenous E6 gene expression. Additionally, high level of miR-875 inhibits cell growth and promotes apoptosis in $\mathrm{SiHa}$ cells [23]. These results suggest tumor-suppressive functions of miR-875-5p in cancer but up to now this suggestion has not been rigorously tested.

Over-expression and activation of EGFR plays a positive role on cell growth and metastasis in variety of solid tumors including CRC [24-27]. EGFR tyrosine kinase activation leads to activation of numerous of 
intracellular signals, which bring to an end in processes that are critical to tumor progression, including cell growth, epithelial-mesenchymal transition (EMT), metastasis, and angiogenesis. These changes are mediated by numerous of downstream targets of EGFR, including extracellular signalregulated kinase $1 / 2(\mathrm{ERK} 1 / 2)$ and AKT protein kinase [28, 29]. Although EGFR signaling pathway is crucial and is well studied in CRC progression, how miR-875-5p mediated EGFR signaling to modulate $\mathrm{CRC}$ progression is little known.

The goal for our current study is to explore the biological functions of miR-875-5p on CRC and to investigate the underlying mechanisms of action. We show for the first time that miR-875-5p directly targets and regulates the 3'-UTR of the human EGFR (NM_005228) mRNA, which is up-regulated in many cancers, including CRC. Here, we reported that miR-875-5p is indeed suppressed in primary CRC compared with the matching adjacent normal colorectal tissues, and found 3'-UTR of the human EGFR mRNA is really a target of miR-875-5p. Collectively, we discovered that miR-875-5p suppressed cell proliferation, metastasis, and promoted cell apoptosis by directly targeting $3^{\prime}$-UTR of EGFR in CRC.

\section{RESULTS}

\section{MiR-875-5p is down-regulated in human CRC tissues and cell lines, and benefits for prognosis}

To determine whether miR-875-5p is decreased expression in CRC, we measured miR-875-5p expression in human primary $\mathrm{CRC}$ and pair-matched adjacent colorectal normal tissues by qRT-PCR. We used U6 that is not deregulated in $\mathrm{CRC}$ for normalization. Results demonstrated miR-875-5p expression in the tumors was significantly $(P<0.05)$ reduced (mean $=32 \%$ of decrease $)$ in $92 \mathrm{CRC}$ cancers in comparison to their matched controls among 92 samples analyzed (Figure 1A). Next, we examined miR-875$5 \mathrm{p}$ expression in CRC cell lines, and results demonstrated a lower expression of miR-875-5p in HCT116, LOVO, RKO, LS174T, HCT8, HR28348, SW480, SW620, DLD1 and HT29 cell lines, compared with that of in normal colorectal epithelial cells, NCM460 (Figure 1B). Among the ten CRC cell lines, miR-875-5p decreased the most in HCT116 and SW480 cell lines, thus, we chose HCT116 and SW480 for model of CRC cell lines. In addition, to assess the clinical significance of miR-875-5p, we evaluated the association between its expression with clinic-pathological parameters (i.e., stage, maximum diameter and lymph node metastasis). Results demonstrated miR-875-5p expression levels in CRC patients were significantly corrected with tumor size $(P=0.0057)$, differentiation $(P=0.0007)$, TNM stage $(P=0.0005)$, and lymph node metastasis $(P=0.0048)$. However, miR-875-5p expression was not associated with other clinical characteristics such as age $(P=0.7452)$, gender $(P=0.4916)$ or Tumor site $(P=0.2393)$ in CRC patients (Table 1). Additionally, Kaplan-Meier survival analysis demonstrated that CRC patients with low miR875-5p expression levels ( $\leq 32 \%$ of decrease, $n=66$ ) of had shorter overall survival, in comparison to patients with high miR-875-5p expression levels ( $>32 \%$ of decrease, $n=26$ ) (Figure 1C), which demonstrated decreased expression of miR-875-5p was associated with poor prognosis. Thus, down-regulated expression of miR875-5p might play a crucial role on CRC progression and development.

\section{Expression of EGFR is up-regulated in primary human CRC and negatively expressed related to miR-875-5p}

EGFR is important oncogene that shown strong power of oncogenicity, by promotion of cell growth, migration, invasion and epithelial mesenchymal transition (EMT), as well as inhibition of cell apoptosis in many tumors including CRC [24, 29]. Thus, we next examined EGFR expression in human primary CRC and pairmatched adjacent colorectal tissues, and our western blot results demonstrated that EGFR protein was increased in CRC tissues compared with normal colorectal tissues (4.4fold of increase) (Figure 2A). These results were confirmed by qRT-PCR of EGFR mRNA expression (Figure 2A). Since EGFR is the key role on regulation of cell cycle, aberrations of these three proteins might contribute to human CRC. Moreover, we estimated the association between EGFR mRNA levels and miR-875-5p levels in 92 CRC tissues. Results demonstrated expression levels of EGFR mRNA and miR-875-5p revealed a significantly negative correlation as the results of Pearson correlation analysis $\left(\mathrm{r}^{2}=0.3188, P<0.0001\right)$ (Figure $\left.2 \mathrm{~B}\right)$.

\section{MiR-875-5p targets human EGFR}

We then investigated the potential molecular mechanism of the anti-tumorigenic property of miR-875-5p in CRC cells. Since miRNAs primarily exert their biological functions in animal cells by hampering the expression of target mRNA, we searched different data bases (TargetScan; microRNA.org and PicTar) for its potential targets that exhibited oncogenic properties. EGFR, which harbors one conserved miR-875-5p cognate site, namely, 256-278 of EGFR 3'-UTR) (Figure 3B), is a predicted target of miR-875-5p. Next, we used luciferase reporter assays to determine whether EGFR expression are indeed regulated by miR-875-5p, And results demonstrate that miR-875-5p inhibits luciferase activity by around $46 \%$ in HCT116 cells and $51 \%$ in SW480 cells when the reporter plasmid carried the WT EGFR 3'-UTR (Figure 3C), but no significant inhibition was observed at the reporter plasmid carried a mutant EGFR 3'-UTR. We next examined the role of miR875-5p on the protein expression of EGFR. Our results of western blot demonstrated that miR-875-5p inhibited 
expression of EGFR protein by approximately $65 \%$ and $75 \%$, when compared with blank HCT116 and SW480 cells (Figure 3D), respectively. Our results reveal that miR-875$5 \mathrm{p}$ targets human EGFR by directly binding to the predicted sites in 3'-UTR of EGFR mRNA.

\section{Inhibition of miR-875-5p does not reverse the anticancer efficacy of silence of $E G F R$ expression in vitro}

We next examined the potential tumorigenicity of $E G F R$ in CRC. Silence of EGFR expression by si-EGFR significantly inhibited the expression of EGFR (Figure 4A). Moreover, loss of EGFR expression also contributed to inhibition of CRC cell (both HCT116 and SW480 cells) growth $(65 \%$ or $52 \%$ of decrease in HCT 116 or SW480 cells) (Figure $4 \mathrm{~B}-4 \mathrm{E}$ ) and metastasis $(63 \%$ or $68 \%$ of decrease in migration, $76 \%$ or $73 \%$ of decrease in invasion in HCT116 or SW480 cells) (Figure 4F-4I). In addition, inhibition of EGFR expression promoted apoptosis in CRC cell (8.5-fold of increase or 7.7-fold of increase at caspase 3 activity, 6.5-fold of increase or 7.8-fold of increase at caspase 7 activity in HCT116 or SW480 cells) (Figure 4J-4K). These results further verified the powerful tumorigenicity of EGFR in CRC. Thus, we adopted EGFR for as targeted oncogenes. However, inhibition of miR875-5p does not reverse the anticancer efficacy of silence of EGFR expression in CRC cell lines (both HCT116 and SW480 cells). These results indicate the anticancer efficacy of miR-875-5p is partly attributed to its inhibitory role on EGFR.

\section{MiR-875-5p suppresses tumor growth nude mouse xenograft model}

To validate the tumor suppressive efficiency of miR$875-5 \mathrm{p}$ in vivo, we established a BALB/c nude mouse xenograft model using HCT116 cells. The mice were treated as descript in method part. Our results demonstrated that the tumor volume and weight of mice treated with miR$875-5 \mathrm{p}$ mimic were significantly reduced $(55 \%$ of decrease in tumor weight) relative to that of treated with miR mimic NC (Figure 5A and 5B). This result demonstrates miR-8755 p significantly suppresses the tumorigenicity of HCT116 cells in the nude mouse xenograft model. In addition, our results of western-blot and qRT-PCR demonstrated that the decreased expression (67\% of decrease) of EGFR in tumors developed from miR-875-5p-mimic-treated
A

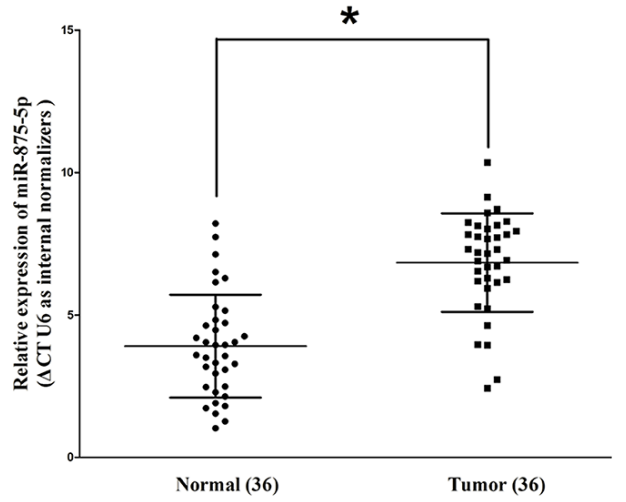

C

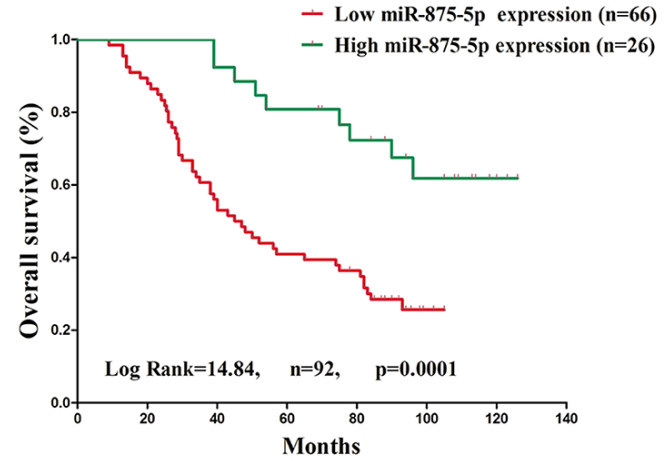

B

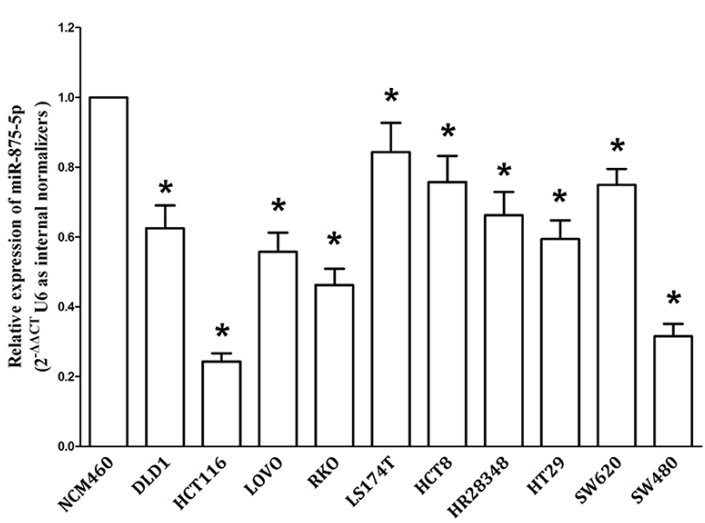

Figure 1: MiR-875-5p is down-regulated in primary human CRC and CRC cell lines, and benefits for prognosis. (A) miR-875-5p is significantly decreased in primary human CRC tissues in comparison to adjacent-normal CRC tissues. $n=36$ for each group. (B) The expression level of miR-875-5p in six CRC cell lines and normal NCM460 cells. Assays were performed in triplicate. (C) Kaplan-Meier survival analysis revealed that down-regulated miR-875-5p is associated with poor prognosis in patients with colorectal carcinoma. ${ }^{*} P<0.001$, Means \pm SEM was shown. Statistical analysis was conducted using student $t$-test and Log Rank test. 
Table 1: Correlation between miR-875-5p expression and clinicopathological parameters of CRC patients $(n=92)$

\begin{tabular}{|c|c|c|c|c|}
\hline \multirow{2}{*}{ Parameter } & \multirow{2}{*}{$n$} & \multicolumn{3}{|c|}{ Relative miR-875-5p expression } \\
\hline & & Low & High & $P$-value [a] \\
\hline Age/years & & & & 0.7452 \\
\hline$\leq 50$ & 40 & 28 & 12 & \\
\hline$>50$ & 52 & 38 & 14 & \\
\hline Gender & & & & 0.4916 \\
\hline Male & 55 & 38 & 17 & \\
\hline Female & 37 & 28 & 9 & \\
\hline Differentiation & & & & $0.0007[*]$ \\
\hline Well, moderate & 60 & 50 & 10 & \\
\hline Poor & 32 & 16 & 16 & \\
\hline Tumor size (cm in diameter) & & & & $0.0057[*]$ \\
\hline$\leq 5 \mathrm{~cm}$ & 36 & 20 & 16 & \\
\hline$>5 \mathrm{~cm}$ & 56 & 46 & 10 & \\
\hline Lymph node metastasis & & & & $0.0048[*]$ \\
\hline Positive & 53 & 32 & 21 & \\
\hline Negative & 39 & 34 & 5 & \\
\hline TMN stage & & & & $0.0005[*]$ \\
\hline I & 23 & 10 & 13 & \\
\hline II/III/IV & 69 & 56 & 13 & \\
\hline Tumor site & & & & 0.2393 \\
\hline Proximal colon & 30 & 19 & 11 & \\
\hline Distal colon & 21 & 14 & 7 & \\
\hline Rectum & 41 & 33 & 8 & \\
\hline
\end{tabular}

${ }^{\mathrm{a}}$ Chi-square test

$* P<0.05$

nude mice relative to that of control tumors (Figure 5C). Moreover, immunohistochemical staining of resected tumor tissues found that tumors formed from miR-875-5ptransfected HCT116 cells exhibited reduced positivity $(78 \%$ of decrease) for Ki67 compared with those formed from control cells (Figure 5D). Thus, miR-875-5p reduces the growth of established colorectal carcinoma xenografts.

\section{MiR-875-5p inhibits CRC cell proliferation and colony formation}

To further explore its anticancer efficacy on CRC cell, we examined the role of miR-875-5p on CRC cell (HCT116 and SW480) proliferation. Our results of BrdU staining revealed that miR-875-5p inhibited HCT116 and SW480 cell DNA synthesis by approximately $60 \%$ (Figure $6 \mathrm{~A}$ and $6 \mathrm{~B}$ ) and $53 \%$ (Figure 6A and 6B), compared with blank HCT116 and SW480 cells, respectively. However, miR-875-5p inhibitor treatment increased HCT116 and SW480 cell DNA synthesis by approximately 2.4 folds (Figure 6A and 6B) and 1.6 folds (Figure 6A and 6B) compared with blank HCT116 and SW480 cells, separately. To verify these results, we also did the CCK8 assay, and results demonstrated that miR-875-5p over-expression significantly attenuated HCT116 and SW480 cells vitality, while loss of miR-875-5p promoted cell proliferation (Figure 6C-6F). In addition, we also investigated the role of miR-875-5p on clonogenic survival, and results demonstrated miR-875-5p mimic treatment caused a decrease in the clonogenic survival of HCT116 and SW480 cells compared with blank HCT116 and blank SW480 cells (Figure 6G and 6H), while miR-875-5p inhibitortreated HCT116 cells showed an significant increase in the clonogenic survival, when compared with blank HCT116 and blank SW480 cells (Figure 6G and 6H). Furthermore, the growth-inhibitory role of miR-875-5p in HCT116 and SW480 cell lines was accompanied by a corresponding decrease in the proportion of cells in the S phase and an increase in the proportion of cells in G1 (Figure 6I and 6J).

We next examined the efficiency of miR-875-5p on expression of EGFR. Our results discovered miR-875-5p significantly inhibited the protein expression of EGFR, 
A

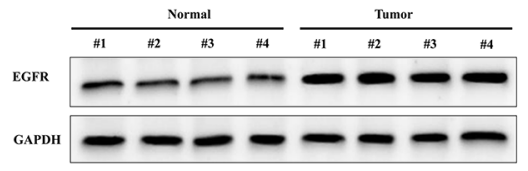

C

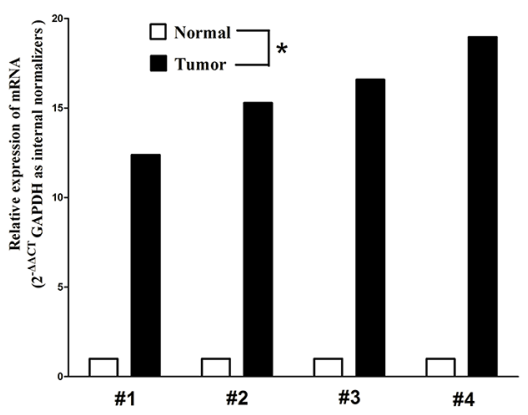

B
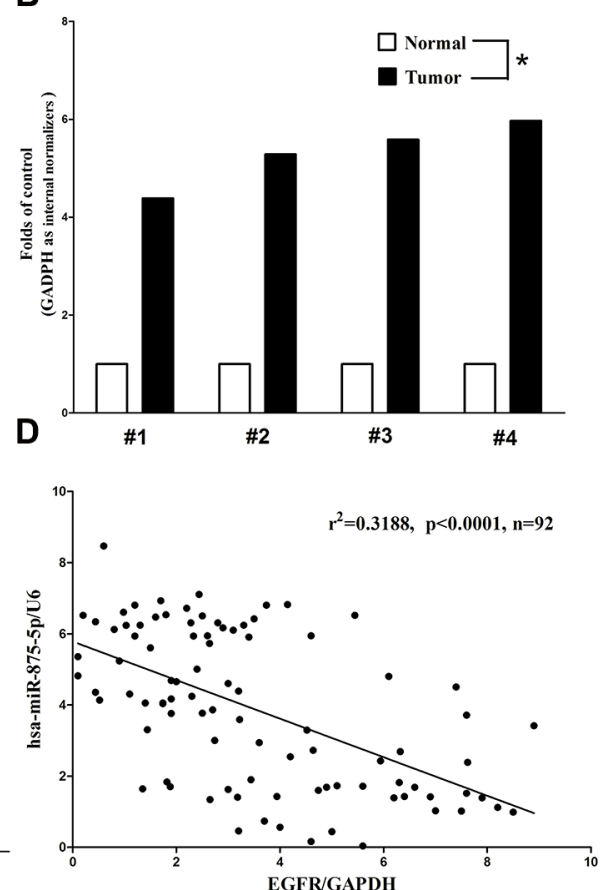

Figure 2: Expression of EGFR is up-regulated in primary human CRC and negatively expressed related to miR-8755p. (A-C) Western-blot of EGFR protein and qRT-PCR of EGFR mRNA in CRC tissues and adjacent-normal CRC. $n=36$ for each group. (D) Scatter plots showing the inverse association between miR-875-5p level and EGFR mRNA expression. ${ }^{*} P<0.001$, Means \pm SEM was shown. Statistical analysis was conducted using student $t$-test and person's correlation analysis.

A

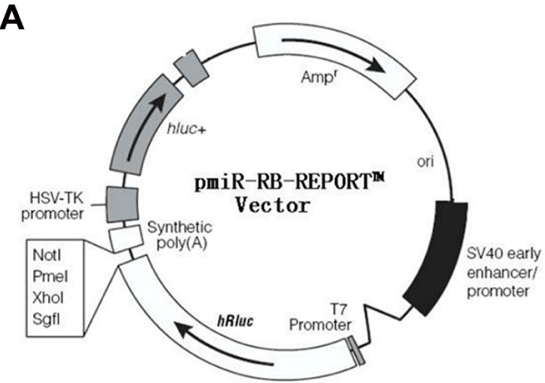

C

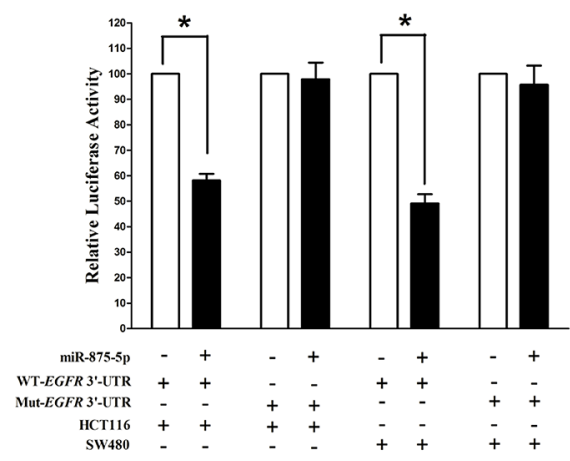

B

hsa-miR-875-5p targets 3'-UTR of EGFR (256-278)

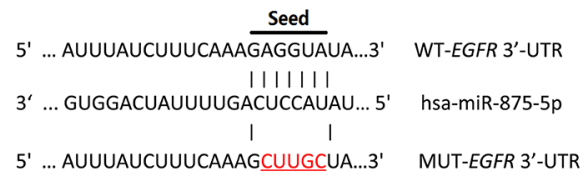

D

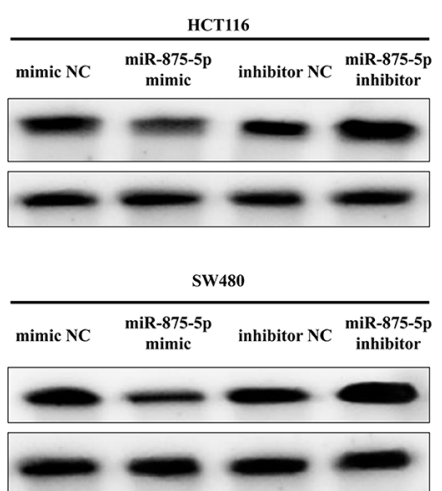

Figure 3: EGFR proto-oncogene is a target of miR-875-5p at specific 3'-UTR sites. (A) pmiR-RB-REPORT TM dualluciferase reporter vector. (B) The 3'-UTR of EGFR harbors one miR-875-5p cognate site. (C) Relative luciferase activity of reporter plasmids carrying wild-type or mutant EGFR 3'-UTR in HCT116 and SW480 cells co-transfected with negative control (NC) or miR-8755p mimic. (D) Protein expression of EGFR in HCT116 and SW480 cells after transfected with related miRNAs. Assays were performed in triplicate. ${ }^{*} P<0.001$, Means \pm SEM was shown. Statistical analysis was conducted using student $t$-test. 
while loss of miR-875-5p remarkably increased the level of EGFR in HCT116 and SW480 cells (Figure 6K). cyclin D2 is highly expressed and promotes tumorigenesis in numerous tumors [30, 31]. In our research, the protein expression of cyclin D2 was repressed by over-expression of miR-875-5p (Figure 6K). Over-expression of CDK4 has been discovered in numerous of malignant neoplasms, including breast cancer, glioma, and CRC [32]. In our research, the protein expression of CDK4 was repressed by over-expression of miR-875-5p in HCT116 and SW480 cells (Figure 6K). Our study revealed over-expression of miR-875-5p is a mechanism for the up-regulation of p57 (a cyclin-dependent kinase inhibitor) level in CRC cell lines (HCT116 and SW480) (Figure 6K). Transfection of p21 (a cell cycle inhibitor) expressive constructs into normal [36] and tumor cell lines [37] leads to cell cycle arrest in G1 [38]. Our study revealed that miR-875-5p up-regulated p21 level in CRC cell lines (HCT116 and SW480) (Figure 6K).

It is concluded that miR-875-5p markedly inhibited cell growth in $\mathrm{CRC}$ cell lines.
A

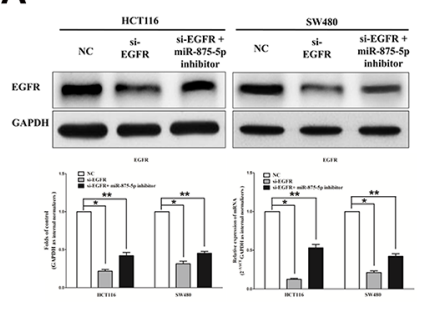

D

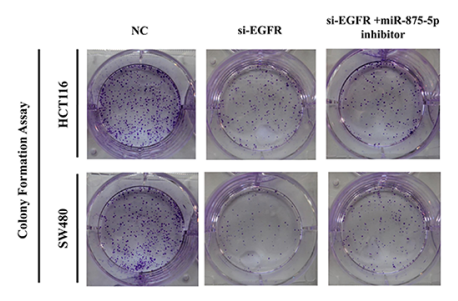

G

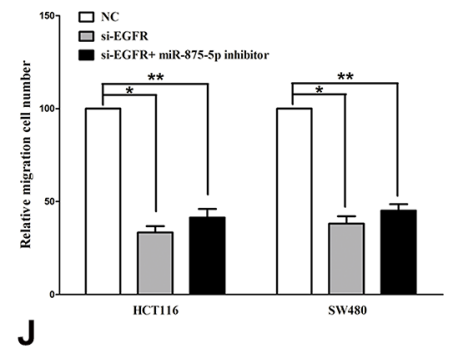

$\mathbf{J}$

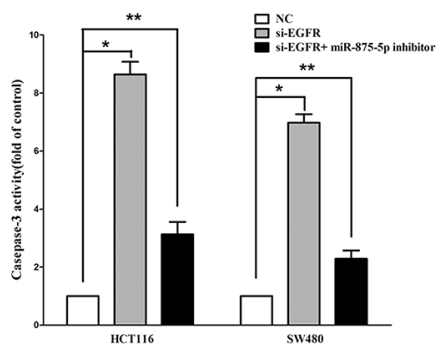

B

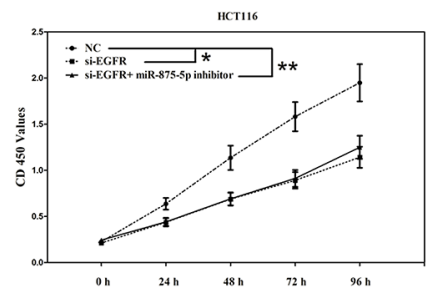

E

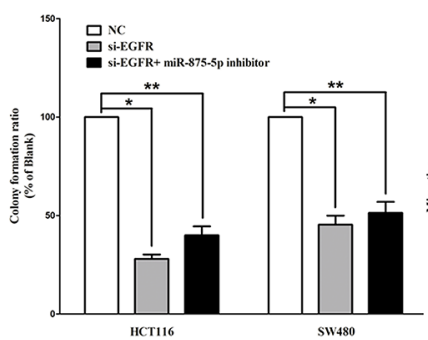

H

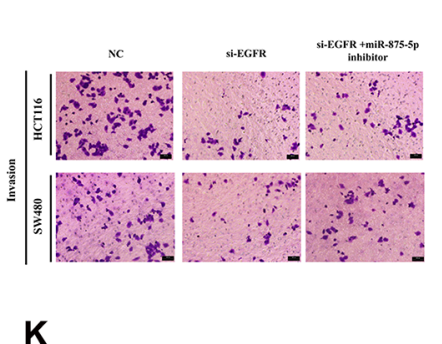

$\mathbf{K}$

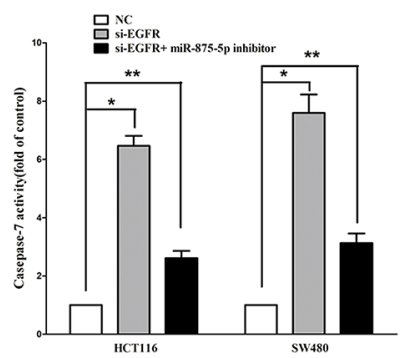

C

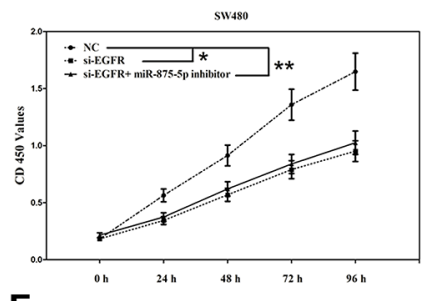

F

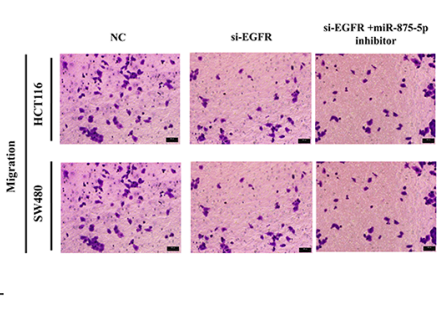

I

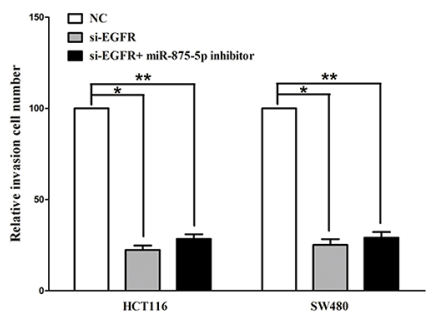

Figure 4: Inhibition of miR-875-5p does not reverse the anticancer efficacy of silence of EGFR expression in vitro. (A) Western-blot of EGFR protein and qRT-PCR of EGFR mRNA in si-EGFR treated and blank HCT116 and SW480 cells, and si-EGFR + miR-875-5p inhibitor. (B-C) CCK8 assays of HCT116 and SW480 cells after transfected (un-transfected) with si-EGFR and si-EGFR + miR-875-5p inhibitor. (D-E) Shown are representative photomicrographs of colony formation assay after transfected with (without) siEGFR and si-EGFR + miR-875-5p inhibitor for fourteen days. (F-G) Shown are representative photomicrographs of transwell migration assay after transfected with (without) si-EGFR and si-EGFR + miR-875-5p inhibitor. (H-I) Shown are representative photomicrographs of transwell invasion assay after transfected with (without) si-EGFR and si-EGFR + miR-875-5p inhibitor. (G-K) Quantitative representation of caspase- 3 and caspase-7 activity in HCT116 and SW480 cells transfected with (without) si-EGFR and si-EGFR + miR-875-5p inhibitor for forty eight hours. Assays were performed in triplicate. ${ }^{*} P<0.001,{ }^{*} P<0.001$, Means \pm SEM was shown. Statistical analysis was conducted using ANOVA. 


\section{MiR-875-5p inhibits CRC cell metastasis}

Invasion and migration through the basement membrane are characteristics of metastatic cancer cells. Then, we explored the role of miR-875-5p on HCT116 and SW480 cells migration and invasion.

We used two different approaches to assess the role of miR-875-5p on HCT116 and SW480 cells migration. In the first technique, we used a "scratch wound healing" assay. Motility of cells at different time points after generation of the wound was monitored under a microscope. Closure of the wound was complete within forty eight hours in control HCT116 and SW480 cells (Figure 7A and 7B). In contrast, miR-875-5p-expressing cells migrated to the wound at a much slower $(60 \%$ of distance or $52 \%$ of distance in HCT116 or SW480 cells) rate (Figure 7A and 7B). In the second approach, we used transwell/migration assay to assess the role of miR-875-5p on cell migration. As expected, migration of miR-875-5pexpressing clones was inhibited by $65 \%$ in HCT 116 and $56 \%$ in SW480 cells, compared with the blank HCT116 and SW480 cells (Figure 7C and 7D), respectively. However, when treated with miR-875-5p inhibitor, migration in miR-875-5p-expression defect HCT116 and
SW480 cells were significantly increased by approximately 2.5 and 2.8 folds relative to blank HCT116 and SW480 cells (Figure 7C and 7D) respectively.

To investigate the role of miR-875-5p on HCT116 and SW480 cells invasion, we used a transwell invasion assay. As expected, invasion of miR-875-5p-expressing clones was inhibited by $68 \%$ in HCT116 and 77\% in SW480 cells, relative to blank HCT116 and SW480 cells (Figure 7C and 7D), respectively. However, when treated with miR-875$5 p$ inhibitor, invasion in miR-875-5p-expression defect HCT116 and SW480 cells were significantly increased by approximately 3.0 and 2.3 folds relative to blank HCT116 and SW480 cells (Figure 7C and 7D), separately.

We also investigated the role of miR-875-5p on expression of MMP-7 and MMP-9, which all play a key role on tumor metastasis, and results indicated miR875-5p inhibited the protein expression of MMP-7 and MMP-9 both in HCT116 and SW480 cells (Figure 7E). As expected, loss of miR-875-5p significantly increased the protein expression of MMP-7 and MMP-9 in both HCT116 and SW480 cells (Figure 7E).

Taken together, these results clearly demonstrated that miR-875-5p expression markedly reduces the migration and invasion motility of CRC cells.
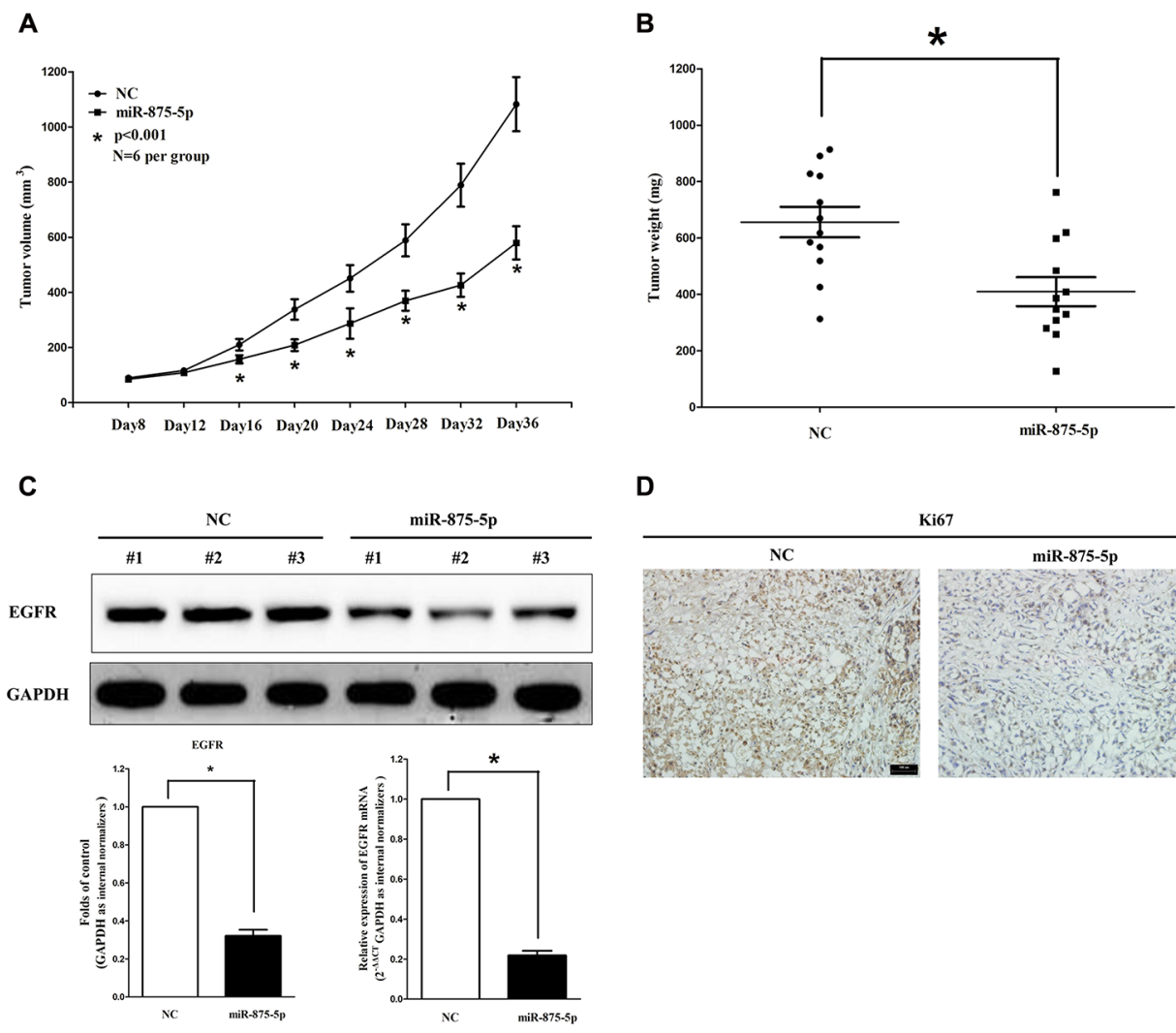

D

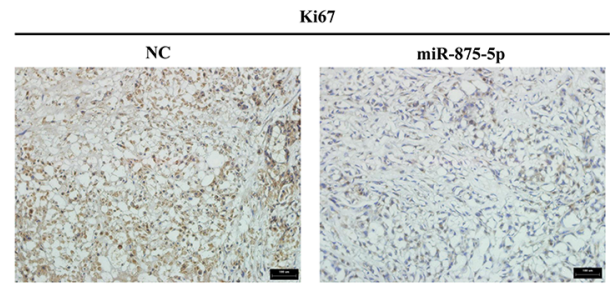

Figure 5: Ectopic expression of miR-875-5p suppresses tumor growth in vivo. (A) Tumor volume in nude mice. (B) Tumor weight in nude mice. Each group contained six mice $(n=6)$; the data are presented as the mean $\pm \mathrm{SEM} ;{ }^{*} p<0.001$, compared with the NC group. (C) The expression of EGFR protein and mRNA in nude mice. Assays were performed in triplicate. $* P<0.001, \mathrm{Means} \pm \mathrm{SEM}$ are shown. Statistical analysis was conducted using student $t$-test. (D) Immunohistochemistry showed miR-875-5p decreased the proliferation index Ki67. 


\section{MiR-875-5p promotes CRC cell apoptosis}

Next, we examined the role of miR-875-5p on HCT116 and SW480 cells apoptosis. Our results of flow cytometric analysis (FCA) revealed that forced expression of miR-875-5p resulted in a $\sim 2.3$ folds and $\sim 1.7$ folds of increase in apoptotic cell death of HCT116 and SW480 cells (Figure 8A), respectively. However, the percentage of apoptotic cells induced by miR-875-5p was decreased to the basal level when the cells were treated with the specific miR-875-5p inhibitor (Figure 8A). In addition, we also tested the caspase- 3 and caspase- 7 activity after treatment of HCT116 and SW480 cells with relative RNAs, and results demonstrated that miR-875-5p remarkably increased caspase- 3 and caspase-7 activities in HCT116 and SW480 cell lysate, by approximately 3.9 and 4.1 folds increase (caspase-3 activity), 2.8 and 3.3 folds increase (caspase-7 activity), than that of in bank HCT116 and SW480 cells (Figure 8B and 8C), respectively. However, loss of miR-875-5p by transfecting with miR-875-5p inhibitor remarkably reduced the caspase- 3 and caspase- 7 activity in HCT116 and SW480 cell lysate, compared with that of
A

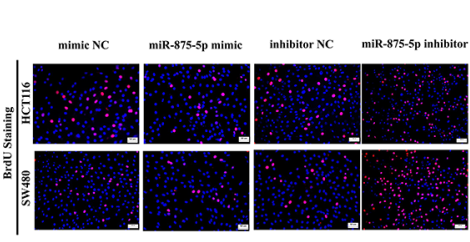

D

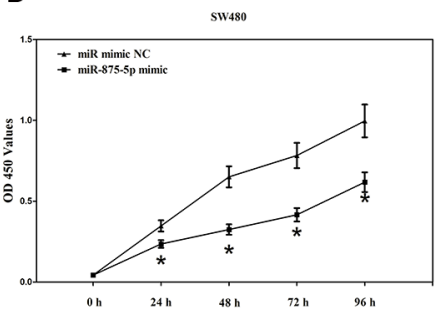

G

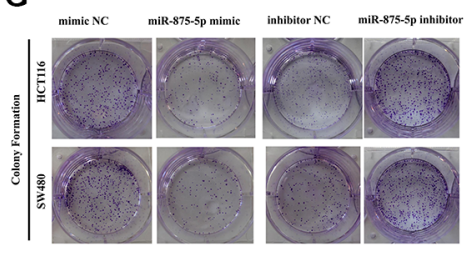

$\mathbf{J}$

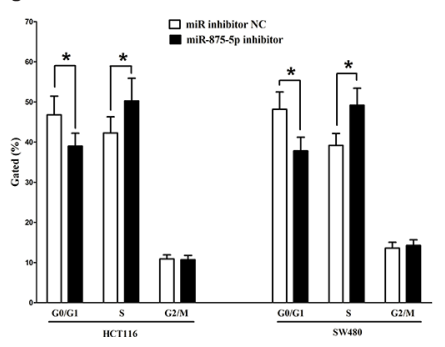

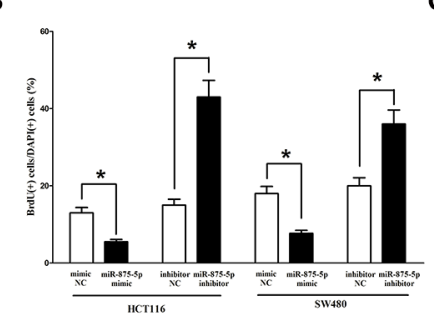

E
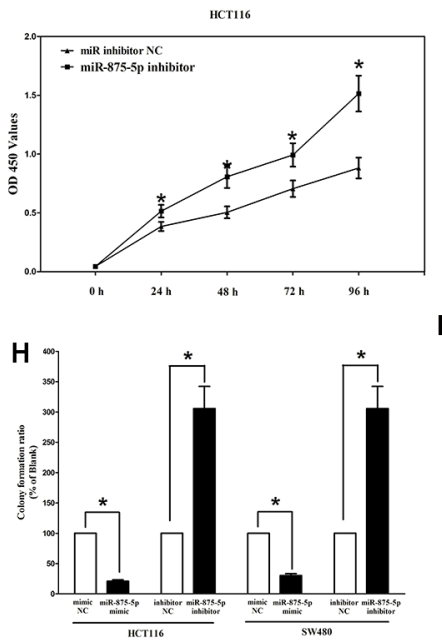

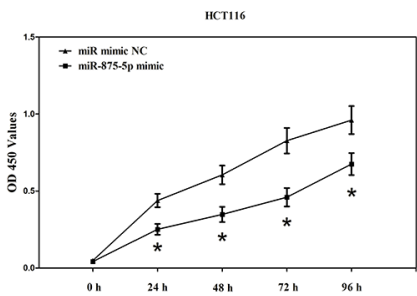

$\mathbf{F}$
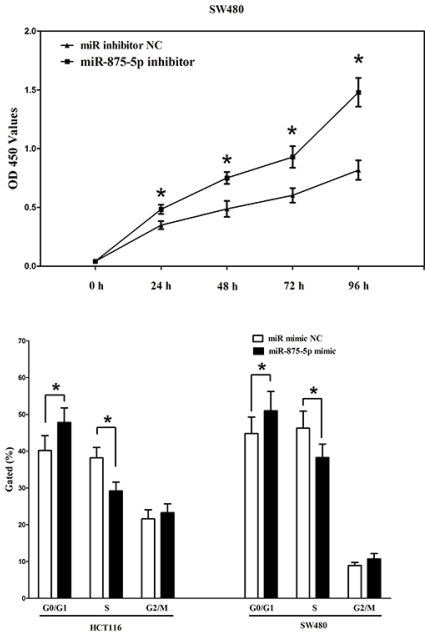

K

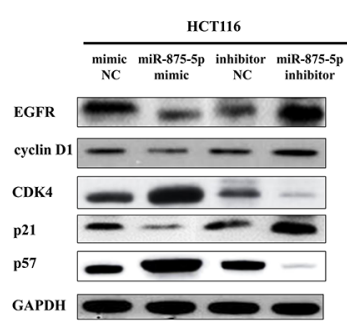

SW480

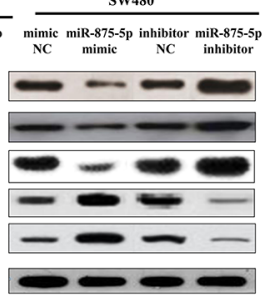

Figure 6: Ectopic expression of miR-875-5p inhibits proliferation and colony formation of HCT116 and SW480 cells. (A) Shown are representative photomicrographs of BrdU staining after transfected HCT116 and SW480 cells with miR-875-5p mimic, miR875-5p mimic NC, miR-875-5p inhibitor or miR-875-5p inhibitor NC for twenty four hours. Bar $=100 \mu \mathrm{m}$. (B) Statistical analysis of BrdU staining. (C-F) CCK8 assays of HCT116 and SW480 cells after transfected with miR-875-5p mimic, miR-875-5p mimic NC, miR-875$5 p$ inhibitor, miR-875-5p inhibitor NC. (G) Shown are representative photomicrographs of colony formation assay after transfected with miR-875-5p mimic, miR-875-5p mimic NC, miR-875-5p inhibitor or miR-875-5p inhibitor NC for fourteen days. (H) Statistical analysis of colony formation assay. Assays were performed in triplicate. (I-J) Cell-cycle analysis was performed forty eight hours following the treatment HCT116 and SW480 cells with miR-875-5p mimic or miR-875-5p mimic NC, miR-875-5p inhibitor or miR-875-5p inhibitor NC. The DNA content was quantified by flow cytometric analysis. (K) Expression of cyclin D1, cyclin D1, CDK4, p21 and p57 protein in transfected HCT116 and SW480 cells. Assays were performed in triplicate. ${ }^{*} P<0.001$, Means \pm SEM was shown. Statistical analysis was conducted using student $t$-test. 
in bank HCT116 and blank SW480 cells (Figure 8B and $8 \mathrm{C})$, respectively. Moreover, miR-875-5p also inhibited the expression level of anti-apoptotic protein Bcl2 (Figure 8D), and increased the protein expression of cleaved-caspase-3 (Figure 8D) in HCT116 and SW480 cells. These results demonstrated that miR-875-5p indeed promoted apoptosis in HCT116 and SW480 cells.

\section{DISCUSSION}

Our present study has revealed the following novel findings: (i) exogenously overexpressed miR-875-5p suppresses tumor regeneration in $6 \mathrm{CRC}$ xenograft models and suppresses cell growth in vitro and in vivo; (ii) miR875-5p overexpression inhibits CRC cells metastasis; (iii) inhibition of miR-875-5p in CRC cells results in high clonal clonogenic, and tumorigenic properties; (iv) miR875-5p overexpression promotes CRC cells apoptosis, and inhibition of miR-875-5p inhibits CRC cell apoptosis; (v) miR-875-5p targets EGFR in CRC cells and negatively expressed with $E G F R$.

$\mathrm{Up}$ to date, the molecular mechanisms about CRC progression are still sparsely elaborated. Hence, a better understanding of the molecular mechanisms referred to tumor formation and development will be helpful to exploit novel therapeutic strategies and targets for treatment of human CRC. Although dysregulation of miRNAs was reported in numerous of human cancers [39], aberrant expression and potential role of miRNAs in CRC were under studied. Our results also indicated that miR-875-5p was decreased in CRC tissues and cell lines, indicating disorder of miR-875-5p is an early event of CRC tumorigenesis.

We therefore explored the speculative tumor suppressive efficiency of miR-875-5p on human CRC cell lines. Firstly, we examined the mechanism of miR875-5p on CRC cell growth, and results indicated restoration of miR-875-5p in the HCT116 and SW480 cells significantly suppressed cell growth as evidenced by colony formation assays, BrdU, and cell viability (CCK8). The growth-inhibitory role of miR-875-5p may be attributed to miR-875-5p targets 3'-UTR of EGFR mRNA, and inhibits the expression of EGFR in CRC cells. In addition, miR-875-5p also inhibited cyclin D1, cyclin D2 and promoted p57 and p21 expression levels in $\mathrm{CRC}$ cells, which further contributed to the growth-delay
A

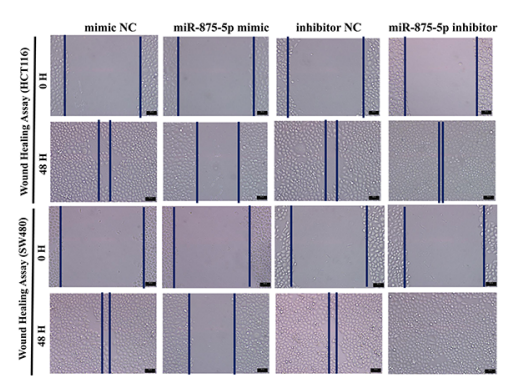

D

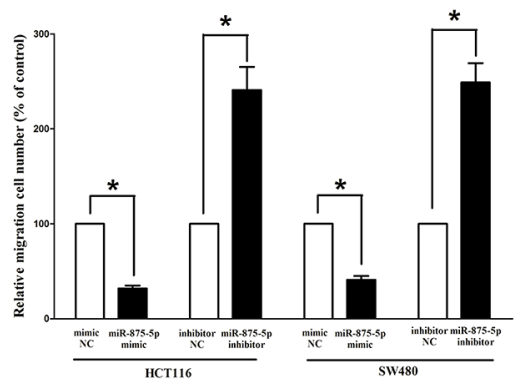

B

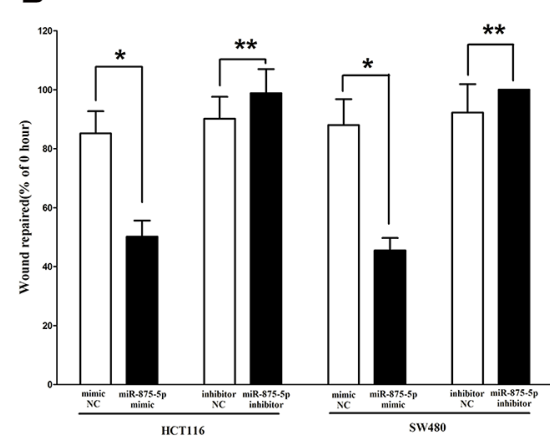$$
\mathbf{E}
$$

E

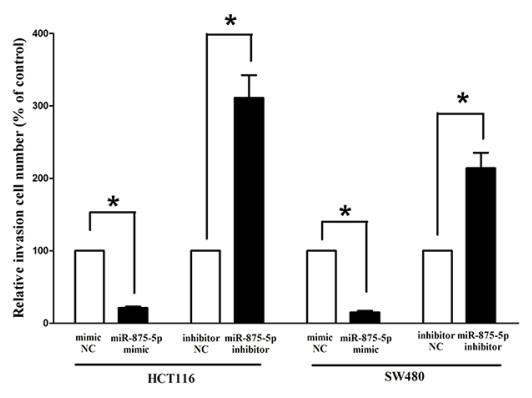

C

$\mathbf{E}$
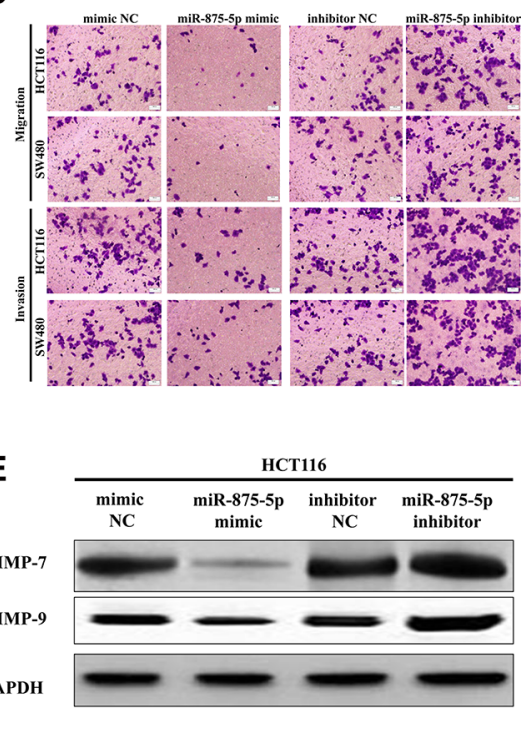

GAPDH

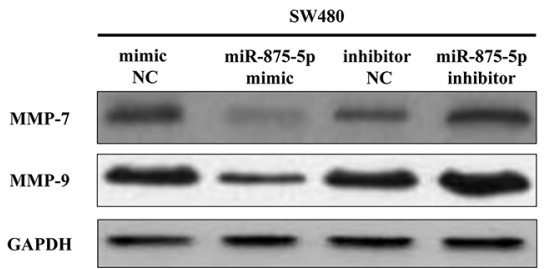

Figure 7: Ectopic expression of miR-875-5p in HCT116 and SW480 cells reduces cell migration and invasion motility. (A) Shown are representative photomicrographs of "wound healing assay" in HCT116 and SW480 cells after transfected miRNAs for 0 hour and forty eight hours. Bar $=100 \mu \mathrm{m}$. (B) Statistical analysis of "wound healing assay". (C) HCT116 and SW480 cells were loaded onto the top well of a transwell inserts for cell migration or invasion assay. After twenty four hours, cells that migrated to the bottom chamber containing serum-supplemented medium were stained with $0.1 \%$ crystal violet, visualized under a phase-contrast microscope, and photographed. Bar $=100 \mu \mathrm{m}$. (D) Total number of cells in five fields was counted manually. (E) Expression of MMP-7 and MMP-9 protein in HCT116 and SW480 cells after transfection. Assays were performed in triplicate. ${ }^{*} P<0.001$, Means \pm SEM was shown. Statistical analysis was conducted using student $t$-test. 
efficacy of miR-875-5p. In addition to inhibition of cell growth, its growth-inhibitory role was also associated with its promotion on cell apoptosis. We discovered that miR$875-5 p$ induced cell apoptosis happens by the regulation of extrinsic apoptosis pathway, which had been viewed as a crucial antitumor mechanism [40-42]. The expression of critical anti-apoptosis protein $\mathrm{Bcl} 2$ was decreased after transfecting with miR-875-5p, and the activity of its downstream factor, active apoptosis executor caspase-3 was up-regulated, leading to initiate a caspase cascade, and finally resulted in cell apoptosis [43].

Restoration of miR-875-5p suppressed the cell metastasis in vitro assays. The reduced disseminating efficiency and cell motility induced by miR-875-5p in $\mathrm{CRC}$ cell lines were demonstrated to be related to decreased protein expression of cell migration and invasion molecules matrix metalloproteinases 7 (MMP-7) and matrix metalloproteinases (MMP-9). MMP-7 and MMP9 are members of the matrix metalloproteinases (MMPs) family, which are located in extracellular and control basic cellular processes, such as morpho-genesis, migration and survival, and they can degrade extracellular matrix during the cancer metastatic process [43, 44]. MMP-7 is an assured rabble-rouser of aggressive behavior in numerous of cancers including CRC. MMP-9 is established as a crucial module for initiating of the pre-metastatic niche [43]. Thus, decreased expression of MMP-7 and MMP-9 by miR-875-5p led to alleviated cell metastasis ability.

Having shown the critical effects of miR-875-5p on suppressing CRC progression, we explored the potential
A

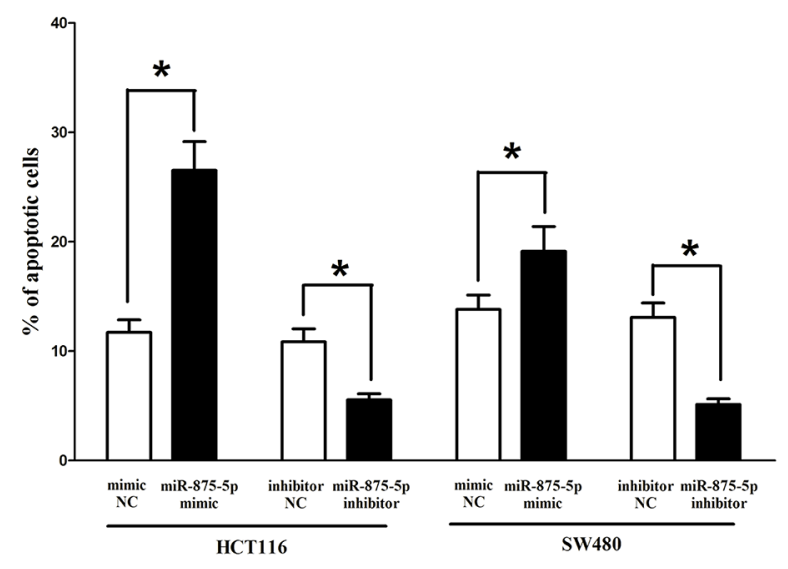

C

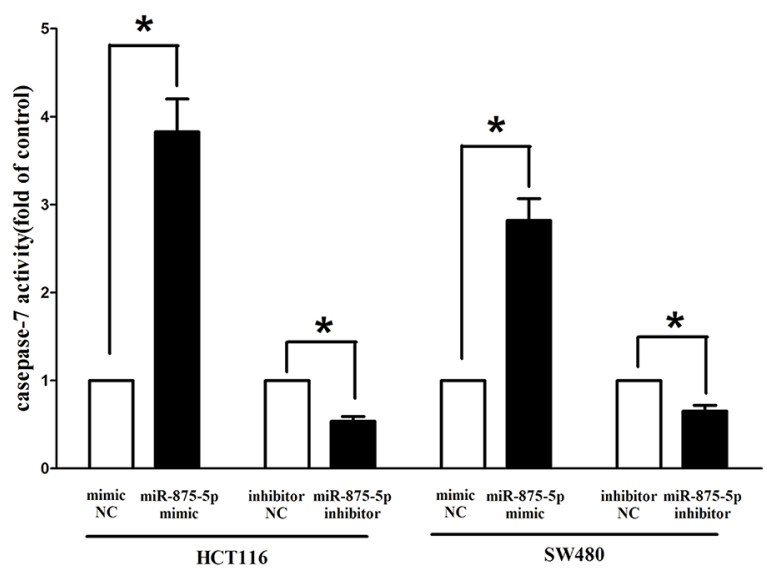

B

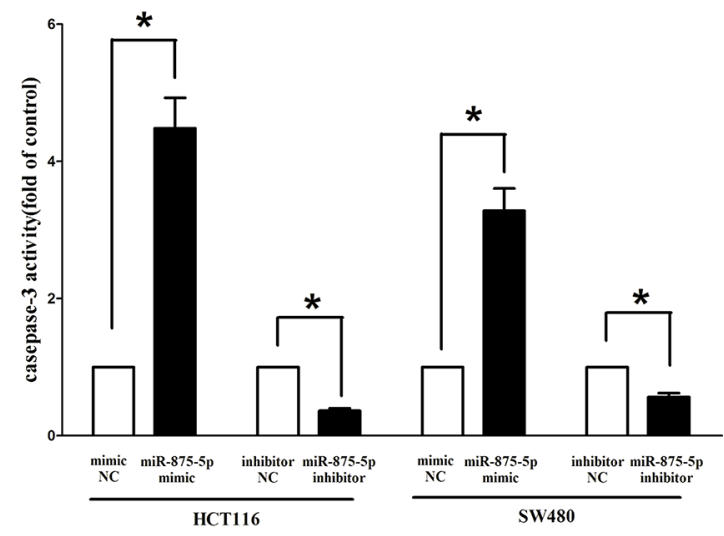

D

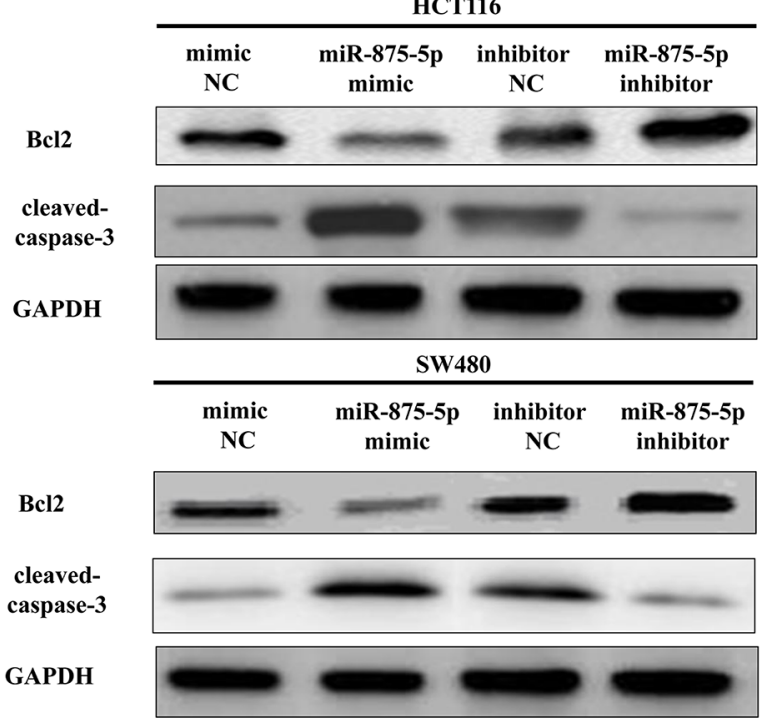

Figure 8: Ectopic expression of miR-875-5p promotes apoptosis in HCT116 and SW480 cells. (A) Shown are statistical analysis of flow cytometric analysis. (B-C) Quantitative representation of caspase-3 and caspase-7 activity in HCT116 and SW480 cells transfected with related miRNAs for forty eight hours. (D) Western-blot of Bcl2 protein in HCT116 and SW480 cells after transfection. Assays were performed in triplicate. $* P<0.001$, Means \pm SEM was shown. Statistical analysis was conducted using student $t$-test. 
gene effectors involving in its function. Amazingly, a single miRNA could affect numerous of target genes coincidently [43], and among the predicted target genes of miR-875-5p, we discovered EGFR acted as a crucial effector of miR-875-5p. Our results demonstrated miR$875-5$ p could significantly inhibit the luciferase activity of wide type of Luc-EGFR-3'-UTR by directly binding with the targeted sites of the 3'-UTR in EGFR mRNA. Therefore we selected EGFR as the target gene, and focused on it for further analysis.

In our present study, we discovered miR-875-5p was an underlying prognostic factor for $\mathrm{CRC}$, and found miR$875-5 p$ is remarkably decreased in human CRC tissues in comparison to normal colorectal tissues. Moreover, we also revealed over-expression of miR-875-5p inhibits cell growth, metastasis, and promotes cell apoptosis in CRC cell lines, through directly targeting EGFR.The present results elucidate a potential mechanism underlying the tumor-suppressor role of miR-875-5p, and indicate that miR-875-5p could be a useful marker and potential therapeutic target in colorectal cancer.

\section{MATERIALS AND METHODS}

\section{Tissue collection}

Fresh and formalin-fixed, paraffin-embedded, CRC tumor tissue samples were obtained from patients who were diagnosed with primary $\mathrm{CRC}$. Elective surgery was carried out on these patients at Shanghai General Hospital of Shanghai Jiaotong University (Shanghai, China). In total, 36 pairs of fresh CRC and adjacent nontumor tissues (more than $5 \mathrm{~cm}$ away from the tumor) were freshly frozen in liquid nitrogen and stored at $-80^{\circ} \mathrm{C}$ until further use. 92 cases of archived, formalin-fixed, paraffinembedded CRC tissue samples were collected and used in clinicopathological and prognostic investigation of miR-875-5p. A comprehensive set of clinicopathological data were recorded, including age, gender, size of primary tumor, tumor differentiation, $\mathrm{T}$ stage, lymph node metastasis, and distant metastasis. The stage of disease was determined according to the tumor size, lymph node, and metastasis (pTNM) classification system. The use of tissues for this study has been approved by the ethics committee of Shanghai General Hospital of Shanghai Jiaotong University. Before using these clinical materials for research purposes, all the patients have signed the informed consent. None of these patients received any pre-operative chemotherapy or radiotherapy.

\section{Cell Culture and transfection}

Ten CRC cell lines (DLD1, HCT116, LOVO, RKO, LS174T, HCT8, HR28348, HT29, SW620, and SW480) and the NCM460 cell lines were purchased from the Institute of Biochemistry and Cell Biology of the Chinese Academy of Sciences (Shanghai, China). Cells were cultured in RPMI
1640 or DMEM (Gibco, Grand Island, NY, USA) medium supplemented with $10 \%$ fetal bovine serum (10\% FBS), $100 \mathrm{U} / \mathrm{ml}$ penicillin, and $100 \mathrm{mg} / \mathrm{ml}$ streptomycin (Gibco) in humidified air at $37^{\circ} \mathrm{C}$ with $5 \% \mathrm{CO} 2$. Hsa-miR-875$5 \mathrm{p}$ mimic and mimic negative control, hsa-miR-875-5p inhibitor and inhibitor negative control were purchased from GenePharma Co.,Ltd. (Shanghai, China). For convenience, hsa-miR-875-5p mimic and mimic negative control, hsa-miR-875-5p inhibitor and inhibitor negative control were simply referred to as $\mathrm{miR}-875-5 \mathrm{p}$ mimic and miR mimic NC, miR-875-5p inhibitor and miR inhibitor $\mathrm{NC}$, respectively. Complete medium without antibiotics was used to culture the cells at least twenty-four hours prior to transfection. The cells were washed with $1 \times$ PBS (pH7.4) and then transiently transfected with $50 \mathrm{nM}$ miR-875-5p mimic or miR mimic NC, $100 \mathrm{nM}$ miR-875-5p inhibitor or miR inhibitor NC, using Lipofectamine ${ }^{\mathrm{TM}} 2000$ (Invitrogen, Carlsbad, CA, USA) according to the manufacturer $>\mathrm{S}$ instructions.

\section{Protein extraction and western blotting}

Cells were rinsed twice with cold PBS and lysed by RIPA buffer (Thermo Fisher Scientific, Waltham, MA, USA) containing protease inhibitor cocktail (Roche). Protein (40 $\mu$ g per sample) was separated by SDS-PAGE using a $10 \%$ polyacrylamide gel. The proteins were transferred electrophoretically onto a PVDF membrane. Blotted membranes were blocked in 5\% skimmed milk diluted in TBST, followed by incubation with appropriate primary antibodies (anti-EGFR, anti-cyclin D1, CDK4, anti-cyclin D2, anti-p21, anti-p57, anti-MMP-7, anti-MMP-9, anticleaved caspase 3, and anti-GADPH; obtained from Cell Signaling Technology and all the antibodies were diluted 1:1000.) overnight at $4^{\circ} \mathrm{C}$. The membranes were then washed for 5 minutes for three times with TBST, and subsequently incubated for 1 hour with HRP-linked secondary antibody (Cell Signaling Technology) at room temperature. GADPH was used as an internal control. The blots were detected using an enhanced chemiluminescence kit (Millipore) and subjected to autoradiography using X-ray film.

\section{RNA isolation and quantitative reverse transcription poly-merase chain reaction (qRT-PCR)}

Total RNA from the cultured cells was extracted using Trizol reagent (Invitrogen) according to the manufacturer's instructions. MiRNA levels were measured by qRT-PCR. For the qRT-PCR detection of mature miR875-5p expression, we purchased the Bulge-Loop ${ }^{\mathrm{TM}}$ miRNA qRT-PCR Primer Set and the miRNA qRT-PCR Control Primer Set (both from RiboBio). RNA ( $2 \mu \mathrm{g})$ was converted into cDNA using the PrimeScript ${ }^{\mathrm{TM}} \mathrm{RT}$ reagent kit with gDNA Eraser (Takara, Dalian, China) according to the manufacturer's instructions. qRT-PCR was performed using SYBR ${ }^{\circledR}$ Premix Ex Taq ${ }^{\mathrm{TM}}$ II (Takara) in the ABI 
PRISM $^{\circledR} 7300$ real-time PCR system (Applied Biosystems, Foster City, CA,USA). GADPH and U6 were used as endogenous controls. In addition, melting curves were used to evaluate non-specific amplification. The relative expression level was calculated using the $2^{-\Delta \Delta \mathrm{Ct}}$ method. The primer sequences used in this study are as follows: the primers of miR-875-5p were purchased from RiboBio (RiboBio Co., Ltd, Guangzhou, China); human EGFR: sense: 5'-CGAATGGGCCTAAGATCCCG-3', antisense: 5'-GGAGCCCAGCACTTTGATCT-3'; human MMP-7: sense: 5'-GAGTGCCAGATGTTGCAGAA-3', antisense: 5'-AAATGCAGGGGGATCTCTTT-3' ; human MMP-9: sense: 5'-CTGCAGTGCCCTGAGGACTA-3', antisense: 5'-ACTCCTCCCTTTCCTCCAGA-3' ; The formula and its derivations were obtained from the ABI Prism 7300 sequence detection system user guide. Statistical analysis was performed on the fold change.

\section{Colony formation assay}

Cells were transfected with miR-875-5p mimic or miR mimic NC, miR-875-5p inhibitor or miR inhibitor NC, as described above. Twenty-four hours later, transfected cells were trypsinized, counted and replated at a density of 1000 cells $/ 6 \mathrm{~cm}$ dish. The medium was changed every three days. After ten days, the cells were washed with PBS, fixed with 4\% paraformaldehyde for 30 minutes, and then stained with crystal violet for 30 minutes for visualization and counting. Colonies containing at least 50 cells were scored. Each assay was performed in triplicates.

\section{Luciferase reporter assays}

The 3'-untranslated region (UTR) of human $E G F R$ was amplified from human genomic DNA and individually inserted into the pmiR-RB-REPORT TM (Ribobio, Guangzhou, China) using the XhoI and NotI sites. Similarly, the fragment of EGFR 3'-UTR mutant was inserted into the pmiR-RB-REPORT TM control vector at the same sites. For reporter assays, HCT116 cells were cotransfected with wild-type (mutant) reporter plasmid and miR-875-5p mimics (miR mimic NC) using Lipofectamine 2000 (Invitrogen). Firefly and Renilla luciferase activities were measured in cell lysates using the Dual-Luciferase Reporter Assay system. Luciferase activity was measured forty-eight hours post-transfection using dual-glo luciferase reporter system according to the manufacturer's instructions (Promega, Madison, WI, USA). Firefly luciferase units were normalized against Renilla luciferase units to control for transfection efficiency.

\section{Transwell migration/invasion assay}

HCT116 and SW480 cells were grown in RPMI 1640 containing $10 \%$ fetal bovine serum to $\sim 60 \%$ confluence and transfected with $50 \mathrm{nM}$ miR-875-5p mimic or a negative control, $100 \mathrm{nM}$ miR-875-5p inhibitor or a negative control. After twenty-four hours, the cells were harvested by trypsinization and washed once with Hanks' balanced salt solution (Invitrogen). To measure cell migration, 8-mm pore size culture inserts (Transwell; Costar, High Wycombe, UK) were placed into the wells of 24-well culture plates, separating the upper and the lower chambers. In the lower chamber, $500 \mu \mathrm{L}$ of RPMI 1640 containing 10\% FBS was added. Then, serum-free medium containing $5 \times 10^{4}$ cells were added to the upper chamber for migration assays, whereas $1 \times 10^{5}$ cells were used for matrigel invasion assays. After twenty-four hours of incubation at $37^{\circ} \mathrm{C}$ with $5 \% \mathrm{CO}_{2}$, the number of cells that had migrated through the pores was quantified by counting 10 independent visual fields under the microscope (Olympus) using a $\times 20$ magnifications, and cell morphology was observed by staining with $0.1 \%$ crystal violet. Filters were washed thoroughly with $1 \times$ PBS and dissolved in $500 \mu \mathrm{L}$ of $33 \%$ acetic acid, and absorbance was measured at $570 \mathrm{~nm}$. Absorbance of cells incubated in the serum-free medium in the bottom chamber was used as negative control. Each experiment was performed at least three times.

\section{BrdU immunofluorescence assay}

HCT116 and SW480 cells were seeded on sterile cover glasses placed in the 6-well plates. After transfection with miR-875-5p mimic, miR mimic NC, miR-875-5p inhibitor, miR inhibitor NC for forty eight hours, the BrdU (5-bromo2-deoxyuridine; Sigma) stock solution at $10 \mathrm{mg} / \mathrm{mL}$ in saline was diluted $1000 \times$ in the culture medium and incubated for $60 \mathrm{~min}$. After washing with $1 \times$ PBS, cells were then fixed for $20 \mathrm{~min}$ in $4 \%$ paraformaldehyde (PFA) and permeabilized with $0.3 \%$ Triton X-100 for $10 \mathrm{~min}$. After blocking with $10 \%$ goat serum in $1 \times$ PBS for $1 \mathrm{~h}$, cells were incubated with a primary rabbit antibody against BrdU (1:200, Abcam) over night at $4^{\circ} \mathrm{C}$, and then incubated with the secondary antibody coupled to a fluorescent marker, $\mathrm{Cy} 3$, at room temperature for $2 \mathrm{~h}$. After DAPI staining and $1 \times$ PBS washing, the cover slips were mounted on to glass slides with anti-fade solution and visualized using a fluorescence microscope (Olympus 600 auto-biochemical analyzer, Tokyo, Japan) with Image-Pro Plus software for image analysis, and 10 microscopic fields were taken for calculating BrdU.

\section{CCK8 assay}

Cell growth was measured using the cell proliferation reagent WST-8 (Roche Biochemicals, Mannheim, Germany). After plating cells in 96-well microtiter plates (Corning Costar, Corning, NY) at $1.0 \times 10^{3} /$ well, $10 \mu \mathrm{L}$ of CCK8 was added to each well at the time of harvest, according to the manufacturer's instructions. One hour after adding CCK8, cellular viability was determined by measuring the absorbance of the converted dye at $450 \mathrm{~nm}$. 


\section{Tumor formation in BALB/c nude mice}

BALB/c athymic nude mice (male, 4-6-weeks old and 16-20 g) were purchased from Hubei Research Center of Laboratory Animal (Wuhan, China). All animal experiments were carried out in accordance with the Guide for the Care and Use of Laboratory Animals of Wuhan University. To establish CRC xenograft model, $5 \times 10^{5}$ HCT116 cells were suspended in $100 \mu \mathrm{L}$ phosphatebuffered saline and inoculated subcutaneously into the flanks of nude mice. After 8 days, the transplanted nude mice were randomly divided into two groups ( $n=6$ each). miR-875-5p mimic (miR-875-5p) or miR mimic NC (NC) (RiboBio Co., Ltd, Guangzhou, China) was directly injected into the implanted tumor at the dose of $1 \mathrm{nmol}$ (in $20 \mu \mathrm{L}$ phosphate-buffered saline) per mouse every 4 days for seven times. The tumor size was monitored by measuring the length (L) and width (W) with calipers every 4 day, and the volumes were calculated using the formula: $\left(\mathrm{L} \times \mathrm{W}^{2}\right) / 2$. Mice were killed by cervical dislocation in day 28, and the tumors were excised and snap-frozen for protein and RNA extraction.

\section{Immunohistochemistry}

Immunohistochemistry of the tumor tissues was performed as described previously [44-48]. 3- $\mu \mathrm{m}$ tumor sections were incubated with commercial rabbit polyclonal antibodies against Ki67 (Affinity) at 1/100 dilution overnight at $4{ }^{\circ} \mathrm{C}$. Then, the sections were conjugated with horseradish peroxidase (HRP) antibody (1:500 dilution; Santa Cruz Biotechnology, Santa Cruz, CA) at room temperature for $2 \mathrm{~h}$, then covered by DAB (Vector Laboratories, Burlingame, $\mathrm{CA}$ ), and slides were mounted with Vectashield mounting medium (Vector Laboratories). Subsequently, all fields were observed under light microscopy (Olympus 600 autobiochemical analyzer, Tokyo, Japan). Control experiments without primary antibody demonstrated that the signals observed were specific.

\section{Flow cytometry}

\section{Apoptosis analysis}

HCT116 and SW480 cells transfected with miR-875-5p mimic or negative control were trypsinized and resuspended in $1 \times$ binding buffer at $1 \times 10^{6}$ cells $/ \mathrm{mL} .100 \mu \mathrm{L}$ of this cell suspension was incubated with $5 \mu \mathrm{L}$ of FITC-Annexin $\mathrm{V}$ and $5 \mu \mathrm{L}$ propridium iodide (PI) for 15 minutes in the dark. The reaction was terminated with the addition of $400 \mu \mathrm{L}$ $1 \times$ binding buffer and analyzed with FACSCalibur using the CellQuest software (Becton Dickinson). FITCAnnexin V-positive and PI-negative cells were considered as apoptotic and the experiments were carried out in triplicates.

\section{Cell-cycle analysis}

Transfected cells were harvested forty-eight hours after transfection. The cells were fixed in $70 \%$ ethanol, washed once with PBS, and then labeled with propidium iodide (Sigma-Aldrich) in the presence of RNase A (Sigma-Aldrich) for $30 \mathrm{~min}$ in the dark (50 g/ $\mathrm{mL}$ ). Samples were run on a FACSalibur flow cytometer (Becton-Dickinson, FL, NJ, USA), and the percentages of cells within each phase of the cell cycle were analyzed using Cell Quest software.

\section{Wound healing assay in vitro}

The HCT116 and SW480 cells were seeded in 6-well plates and incubated for twenty-four hours. Then a linear wound was tehncreated by dragging a $100-\mu \mathrm{L}$ pipette tip through the monolayer prior to transfection. Cellular debris was removed by gentle washes with culture medium, following which transfection was performed immediately, and the cells were allowed to migrate for a further forty-eight hours. The healing process was dynamically photographed after the wound was introduced using a microscope (Olympus 600 auto-biochemical analyzer, Tokyo, Japan). Migration distance was measured from images (5 fields) taken at each indicated time point. The gap size was analyzed using Image-Pro Plus 6.0 software. The residual gap between the migrating cells from the opposing wound edge was expressed as a percentage of the initial gap size.

\section{Caspase-3/7 activity assay}

The activity of caspase-3/7 was determined using the caspase- $3 / 7$ activity kit (Beyotime Institute of Biotechnology, Haimen, China).To evaluate the activity of caspase-3/7, cell lysates were prepared after their respective treatment with various designated treatments. Assays were performed on 96-well microtitre plates by incubating $10 \mu \mathrm{L}$ protein of cell lysate per sample in $80 \mu \mathrm{L}$ reaction buffer (1\% NP-40, $20 \mathrm{mM}$ Tris-HCl (pH 7.5), $137 \mathrm{mM}$ Nad and $10 \%$ glycerol) containing $10 \mu \mathrm{L}$ caspase-3 substrate (AcDEVD-pNA) (2 mM). Lysates were incubated at $37^{\circ} \mathrm{C}$ for $4 \mathrm{~h}$. Samples were measured with an ELISA reader at an absorbance of $405 \mathrm{~nm}$. The detail analysis procedure was described in the manufacturer's protocol.

\section{Statistical analysis}

All experiments were repeated 3 times independently. The results are presented as the means \pm standard error mean (SEM). Two independent sample $t$-test or One-Way Analysis of Variance (ANOVA) was performed using SPSS 19.0 software in order to detect significant differences in measured variables among groups. A value of $P<0.05$ was considered to indicate a statistically significant difference. 


\section{Abbreviations}

The abbreviations used are: used: miR, microRNA; miR-875-5p, has-microRNA-875-5p; colorectal carcinoma, CRC; 3'-untranslated region, 3'-UTR; B-cell lymphoma-2, BCL2.

\section{CONFLICTS OF INTEREST}

The authors declare that they have no competing interests.

\section{FUNDING}

This work was supported by the Chinese Society of Clinical Oncology-Merck Serono Research Fund for Oncology Experts (Y-MX2015-015).

\section{Authors' contributions}

Participated in research design: Tiening Zhang, Qi Li, Peng Xue, Zhixiao Chen, Xiao Dong, Ying Xue and Xun Cai. Conducted experiments: Tiening Zhang, Qi Li, Peng Xue, Zhixiao Chen, Xiao Dong, Ying Xue and Xun Cai. Contributed new reagents or analytic tools: Tiening Zhang, Qi Li, Peng Xue, Zhixiao Chen, Xiao Dong, Ying Xue and Xun Cai. Performed data analysis: Tiening Zhang, Qi Li, Peng Xue, Zhixiao Chen, Xiao Dong, Ying Xue and Xun Cai. Wrote or contributed to the writing of the manuscript: Tiening Zhang, Qi Li, Peng Xue, Zhixiao Chen, Xiao Dong, Ying Xue and Xun Cai.

\section{REFERENCES}

1. DeSantis CE, Lin CC, Mariotto AB, Siegel RL, Stein KD, Kramer JL, Alteri R, Robbins AS, Jemal A. Cancer treatment and survivorship statistics, 2014. CA Cancer J Clin. 2014; 64:252-271.

2. Sanoff HK, Sargent DJ, Campbell ME, Morton RF, Fuchs CS, Ramanathan RK, Williamson SK, Findlay BP, Pitot HC, Goldberg RM. Five-year data and prognostic factor analysis of oxaliplatin and irinotecan combinations for advanced colorectal cancer: N9741. J Clin Oncol. 2008; 26:5721-5727.

3. Shen K, Liang Q, Xu K, Cui D, Jiang L, Yin P, Lu Y, Li Q, Liu J. MiR-139 inhibits invasion and metastasis of colorectal cancer by targeting the type I insulin-like growth factor receptor. Biochem Pharmacol. 2012; 84:320-330.

4. Sung JJ, Ng SC, Chan FK, Chiu HM, Kim HS, Matsuda T, Ng SS, Lau JY, Zheng S, Adler S, Reddy N, Yeoh KG, Tsoi KK, et al. An updated Asia Pacific Consensus Recommendations on colorectal cancer screening. GUT. 2015; 64:121-132.

5. Torre LA, Bray F, Siegel RL, Ferlay J, Lortet-Tieulent J, Jemal A. Global cancer statistics, 2012. CA Cancer J Clin. 2015; 65:87-108.
6. De Rosa M, Pace U, Rega D, Costabile V, Duraturo F, Izzo P, Delrio P. Genetics, diagnosis and management of colorectal cancer (Review). Oncol Rep. 2015; 34:1087-1096.

7. Sung JJ, Lau JY, Young GP, Sano Y, Chiu HM, Byeon JS, Yeoh KG, Goh KL, Sollano J, Rerknimitr R, Matsuda T,

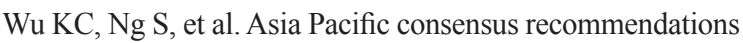
for colorectal cancer screening. GUT. 2008; 57:1166-1176.

8. Rerknimitr R, Angsuwatcharakon P, Ratanachu-ek T, Khor CJ, Ponnudurai R, Moon JH, Seo DW, Pantongrag-Brown L, Sangchan A, Pisespongsa P, Akaraviputh T, Reddy ND, Maydeo A, et al. Asia-Pacific consensus recommendations for endoscopic and interventional management of hilar cholangiocarcinoma. J Gastroenterol Hepatol. 2013; 28: 593-607.

9. Chen H, Li L, Wang S, Lei Y, Ge Q, Lv N, Zhou X, Chen C. Reduced miR-126 expression facilitates angiogenesis of gastric cancer through its regulation on VEGF-A. Oncotarget. 2014; 5:11873-11885. doi: 10.18632/ oncotarget.2662.

10. Zhang Y, Zhao FJ, Chen LL, Wang LQ, Nephew KP, Wu YL, Zhang S. MiR-373 targeting of the Rab22a oncogene suppresses tumor invasion and metastasis in ovarian cancer. Oncotarget. 2014; 5:12291-12303. doi: 10.18632/ oncotarget. 2577.

11. Mei Q, Xue G, Li X, Wu Z, Li X, Yan H, Guo M, Sun S, Han W. Methylation-induced loss of miR-484 in microsatelliteunstable colorectal cancer promotes both viability and IL-8 production via CD137L. J Pathol. 2015; 236:165-174.

12. Diaz-Martin J, Diaz-LopezA, Moreno-Bueno G, Castilla MA, Rosa-Rosa JM, Cano A, Palacios J. A core microRNA signature associated with inducers of the epithelial-tomesenchymal transition. J Pathol. 2014; 232:319-329.

13. Hsu CY, Hsieh TH, Tsai CF, Tsai HP, Chen HS, Chang Y, Chuang HY, Lee JN, Hsu YL, Tsai EM. miRNA-199a-5p regulates VEGFA in endometrial mesenchymal stem cells and contributes to the pathogenesis of endometriosis. J Pathol. 2014; 232:330-343.

14. Ivey KN, Srivastava D. MicroRNAs as regulators of differentiation and cell fate decisions. Cell Stem Cell. 2010; 7:36-41.

15. Hatfield SD, Shcherbata HR, Fischer KA, Nakahara K, Carthew RW, Ruohola-Baker H. Stem cell division is regulated by the microRNA pathway. Nature. 2005; 435:974-978.

16. Mendell JT, Olson EN. MicroRNAs in stress signaling and human disease. Cell. 2012; 148:1172-1187.

17. Sun C, Li S, Zhang F, Pan J, Yang C, Xi Y, Wang L, Li D. Hsa-miR-329 exerts tumor suppressor function through down-regulation of MET in non-small cell lung cancer. Oncotarget. 2016; doi: 10.18632/oncotarget.7517.

18. Sun C, Liu Z, Li S, Yang C, Xue R, Xi Y, Wang L, Wang S, He Q, Huang J, Xie S, Jiang W, Li D. Down-regulation of c-Met and $\mathrm{Bcl} 2$ by microRNA-206, activates apoptosis, and inhibits tumor cell proliferation, migration and colony formation. Oncotarget. 2015; 6:25533-25574. doi: 10.18632/ oncotarget. 4575 . 
19. Sun C, Huang C, Li S, Yang C, Xi Y, Wang L, Zhang F, Fu Y, Li D. Hsa-miR-326 targets CCND1 and inhibits nonsmall cell lung cancer development. Oncotarget. 2016. doi: 10.18632/oncotarget.7071.

20. Sun CC, Li SJ, Zhang F, Pan JY, Wang L, Yang CL, Xi YY, Li DJ. Hsa-miR-329 exerts tumor suppressor function through down-regulation of MET in non-small cell lung cancer. Oncotarget. 2016. doi: 10.18632/oncotarget.7517.

21. Sun C, Li S, Yang C, Xi Y, Wang L, Zhang F, Li D. MicroRNA-187-3p mitigates non-small cell lung cancer (NSCLC) development through down-regulation of BCL6. Biochem Biophys Res Commun. 2016; 471:82-88.

22. Li L, Chen HZ, Chen FF, Li F, Wang M, Wang L, Li YQ, Gao DS. Global microRNA expression profiling reveals differential expression of target genes in 6-hydroxydopamine-injured MN9D cells. Neuromolecular Med. 2013; 15:593-604.

23. Lin L, Cai Q, Zhang X, Zhang H, Zhong Y, Xu C, Li Y. Two less common human microRNAs miR-875 and miR-3144 target a conserved site of E6 oncogene in most high-risk human papillomavirus subtypes. Protein Cell. 2015; 6:575-588.

24. Suriyo T, Tachachartvanich P, Visitnonthachai D, Watcharasit $P$, Satayavivad J. Chlorpyrifos promotes colorectal adenocarcinoma H508 cell growth through the activation of EGFR/ERK1/2 signaling pathway but not cholinergic pathway. Toxicology. 2015; 338:117-129.

25. Chen D, Huang X, Cai J, Guo S, Qian W, Wery JP, Li QX. A set of defined oncogenic mutation alleles seems to better predict the response to cetuximab in CRC patient-derived xenograft than KRAS 12/13 mutations. Oncotarget. 2015; 6:40815-40821. doi: 10.18632/oncotarget.5886.

26. Linardou H, Dahabreh IJ, Kanaloupiti D, Siannis F, Bafaloukos D, Kosmidis P, Papadimitriou CA, Murray S. Assessment of somatic k-RAS mutations as a mechanism associated with resistance to EGFR-targeted agents: a systematic review and meta-analysis of studies in advanced non-small-cell lung cancer and metastatic colorectal cancer. Lancet Oncol. 2008; 9:962-972.

27. Wang RY, Chen L, Chen HY, Hu L, Li L, Sun HY, Jiang F, Zhao J, Liu GM, Tang J, Chen CY, Yang YC, Chang YX, et al. MUC15 inhibits dimerization of EGFR and PI3K-AKT signaling and is associated with aggressive hepatocellular carcinomas in patients. Gastroenterology. 2013; 145:1436-1448.

28. Chang ZG, Wei JM, Qin CF, Hao K, Tian XD, Xie K, Xie XH, Yang YM. Suppression of the epidermal growth factor receptor inhibits epithelial-mesenchymal transition in human pancreatic cancer PANC-1 cells. Dig Dis Sci. 2012; 57:1181-1189.

29. Gan Y, Shi C, Inge L, Hibner M, Balducci J, Huang Y. Differential roles of ERK and Akt pathways in regulation of EGFR-mediated signaling and motility in prostate cancer cells. Oncogene. 2010; 29:4947-4958.

30. Sicinski P, Donaher JL, Geng Y, Parker SB, Gardner H, ParkMY, Robker RL, Richards JS, McGinnis LK, Biggers JD, Eppig JJ, Bronson RT, Elledge SJ, et al. Cyclin D2 is an FSHresponsive gene involved in gonadal cell proliferation and oncogenesis. Nature. 1996; 384:470-474.
31. Vieira FQ, Costa-Pinheiro P, Almeida-Rios D, Graca I, Monteiro-Reis S, Simoes-Sousa S, Carneiro I, Sousa EJ, Godinho MI, Baltazar F, Henrique R, Jeronimo C. SMYD3 contributes to a more aggressive phenotype of prostate cancer and targets Cyclin D2 through H4K20me3. Oncotarget. 2015; 6:13644-13657. doi: 10.18632/oncotarget.3767.

32. Das S, Kumar M, Negi V, Pattnaik B, Prakash YS, Agrawal A, Ghosh B. MicroRNA-326 regulates profibrotic functions of transforming growth factor-beta in pulmonary fibrosis. Am J Respir Cell Mol Biol. 2014; 50:882-892.

33. Italiano A, Bianchini L, Gjernes E, Keslair F, RanchereVince D, Dumollard JM, Haudebourg J, Leroux A, Mainguene C, Terrier P, Chibon F, Coindre JM, Pedeutour F. Clinical and biological significance of CDK4 amplification in well-differentiated and dedifferentiated liposarcomas. Clin Cancer Res. 2009; 15:5696-5703.

34. Mishra S, Lin CL, Huang TH, Bouamar H, Sun LZ. MicroRNA-21 inhibits p57Kip2 expression in prostate cancer. Mol Cancer. 2014; 13:212.

35. Gartel AL, Tyner AL. Transcriptional regulation of the p21((WAF1/CIP1)) gene. Exp Cell Res. 1999; 246: 280-289.

36. Harper JW, Adami GR, Wei N, Keyomarsi K, Elledge SJ. The p21 Cdk-interacting protein Cip1 is a potent inhibitor of G1 cyclin-dependent kinases. Cell. 1993; 75:805-816.

37. El-Deiry WS, Tokino T, Velculescu VE, Levy DB, Parsons R, Trent JM, Lin D, Mercer WE, Kinzler KW, Vogelstein B. WAF1, a potential mediator of p53 tumor suppression. Cell. 1993; 75:817-825.

38. Harper JW, Elledge SJ, Keyomarsi K, Dynlacht B, Tsai LH, Zhang P, Dobrowolski S, Bai C, Connell-Crowley L, Swindell E, Et A. Inhibition of cyclin-dependent kinases by p21. Mol Biol Cell. 1995; 6:387-400.

39. Lu J, Getz G, Miska EA, Alvarez-Saavedra E, Lamb J, Peck D, Sweet-Cordero A, Ebert BL, Mak RH, Ferrando AA, Downing JR, Jacks T, Horvitz HR, et al. MicroRNA expression profiles classify human cancers. Nature. 2005; 435:834-838.

40. Johnstone RW, Frew AJ, Smyth MJ. The TRAIL apoptotic pathway in cancer onset, progression and therapy. Nat Rev Cancer. 2008; 8:782-798.

41. Balkwill F. Tumour necrosis factor and cancer. Nat Rev Cancer. 2009; 9:361-371.

42. Holoch PA, Griffith TS. TNF-related apoptosis-inducing ligand (TRAIL): a new path to anti-cancer therapies. Eur J Pharmacol. 2009; 625:63-72.

43. Zhang L, Dong Y, Zhu N, Tsoi H, Zhao Z, Wu CW, Wang K, Zheng S, Ng SS, Chan FK, Sung JJ, Yu J. microRNA-139$5 \mathrm{p}$ exerts tumor suppressor function by targeting NOTCH1 in colorectal cancer. Mol Cancer. 2014; 13:124.

44. Sun C, Yang C, Xue R, Li S, Zhang T, Pan L, Ma X, Wang L, Li D. Sulforaphane alleviates muscular dystrophy in mdx mice by activation of Nrf2. J Appl Physiol. 2015; 118:224-237.

45. Sun CC, Li SJ, Yang CL, Xue RL, Xi YY, Wang L, Zhao QL, Li DJ. Sulforaphane Attenuates Muscle Inflammation 
in Dystrophin-deficient mdx Mice via NF-E2-related Factor 2 (Nrf2)-mediated Inhibition of NF-kappaB Signaling Pathway. J Biol Chem. 2015; 290:17784-17795.

46. Sun C, Li S, Li D. Sulforaphane mitigates muscle fibrosis in mdx mice via Nrf2-mediated inhibition of TGF-beta/Smad signaling. J Appl Physiol. 1985; 2015:721-2015.

47. Sun C, Sang M, Li S, Sun X, Yang C, Xi Y, Wang L, Zhang F, Bi Y, Fu Y,Li D. Hsa-miR-139-5p inhibits proliferation and causes apoptosis associated with down-regulation of
c-Met. Oncotarget. 2015; 6:39756-39792. doi: 10.18632/ oncotarget.5476.

48. Sun C, Liu Z, Li S, Yang C, Xue R, Xi Y, Wang L, Wang S, He Q, Huang J, Xie S, Jiang W, Li D. Down-regulation of c-Met and Bcl2 by microRNA-206, activates apoptosis, and inhibits tumor cell proliferation, migration and colony formation. Oncotarget. 2015; 6:25533-25574. doi: 10.18632/oncotarget.4575. 